\title{
La edificación de la moral relevante para la política y el Derecho Los aportes de las éticas deontológicas y las éticas comunicativas de raíz kantiana
}

\author{
REYNALDO BUSTAMANTE ALARCÓN*
}

\begin{abstract}
SUMARIO: I. ALGUNAS CATEGORÍAS Y PRECISIONES BÁSICAS.- II. LAS ÉTICAS DEONTOLÓGICAS DE RAÍZ KANTIANA: EL EQUILIBRIO ENTRE LOS PRINCIPIOS DE AUTONOMÍA Y UNIVERSALIDAD, ORIENTADOS POR LA DIGNIDAD HUMANA.- III. LAS ÉTICAS COMUNICATIVAS DE RAÍZ KANTIANA: UNA CONCEPCIÓN CONSTRUCTIVISTA REGIDA POR EL PRINCIPIO DISCURSIVO DE UNIVERSALIZACIÓN Y EL DE ADECUACIÓN.- IV. BREVE REFLEXIÓN FINAL.
\end{abstract}

\section{ALGUNAS CATEGORÍAS Y PRECISIONES BÁSICAS}

La palabra «moral» suele ser tomada con dos significados diferentes: con referencia directa al comportamiento humano y su calificación como bueno o malo, justo o injusto, y como estudio de la moral, aquella parte de la filosofía que estudia los comportamientos humanos en cuanto morales o inmorales, por lo que se habla así de filosofía moral, ética o simplemente moral. ${ }^{1}$ Aquí utilizaremos la palabra «moral» en el primero de sus significados y a «ética» como su sinónimo.

La moral hace referencia a valores, principios y criterios que sirven de guía para la conducta humana. Se expresa de manera más o menos inmediata en normas —en un deber ser-, aunque diferentes a las sociales y a las jurídicas porque proceden, fundamentalmente, del sujeto mismo que se siente obligado por ellas y no de la decisión de terceras personas (su origen y fundamento radica en la conciencia moral autónoma del individuo). ${ }^{2}$ La diferencia con estas figuras no radica realmente en la ausencia de coacción, sino en el origen autónomo de las normas morales y en el heterónomo de las sociales y jurídicas. Mientras que en las primeras la

* ProfesordelDepartamento de Derechodela Pontificia Universidad Católica delPerú. Dedicoesteensayoa Felipe Andrés, mi sobrino, por renovar mi esperanza en un futuro mejor.

1 Véase Aranguren, José Luis L. De ética y de moral, Lo que sabemos de moral, moral de la vida cotidiana, personaly religiosa. Barcelona: Círculo de Lectores, 1991, p. 13. Incluso suele distinguirse entre moral, ética y metaética: a cada moralle correspondería «la tarea de prescribir laconductaen la vida cotidiana, mediante enunciados valorativos o prescriptivos con contenido", que establezcan lo que se debe hacer; a la ética o filosofía moral, la «reflexión sobre las formas de las prescripciones y valoraciones morales, que intenta fundamentarlas»;yalametaética, «lamisióndedilucidarsilaéticaesunadisciplinaautónoma, siesciencia, y de qué modo se contraponen entre sí las distintas articulaciones éticas.” CoRTINA, Adela. Ética sin moral. Quinta edición. Madrid: Tecnos, 2004 [1990], p. 44.

2 Se dice que las normas morales provienen «fundamentalmente» del sujeto mismo que se siente obligado a ellas, porque, si bien tienen su origen en la conciencia moral autónoma del individuo, se pueden nutrir de valores socioculturales. 
coacción proviene exclusivamente de la conciencia moral del propio individuo que se siente compelido a seguirlas, en las dos últimas la coacción reside en el grupo social o en el poder político que las sostiene. De esa manera, y a través de los hábitos del comportamiento, la moral conforma el carácter, el modo de ser de las personas. ${ }^{3}$ Èsta puede clasificarse en personal, social y crítica. ${ }^{4}$

La moral personal suele utilizarse en cualquiera de los siguientes sentidos: para significar que se origina en la conciencia autónoma de la persona, para expresar que corresponde a cada individuo, y para hacer referencia a aquella que tiene que ver exclusivamente con su vida privada.

La moral social suele ser utilizada para denotar la influencia que ejerce la realidad social, en el sentido de que la moral se nutre de valores y normas socioculturales para indicar los valores o normas morales que rigen el comportamiento de los individuos en relación con los demás, es decir, la vida pública o social, y para hacer referencia a la moral de la mayoría o de la totalidad del grupo social: a la moral vigente en una sociedad.

Cuando la moral social o personal no coincide con una recta conciencia o una recta razón, cuando existe una sed de justicia mayor o una discrepancia con el orden moral vigente, puede ocurrir que uno o más individuos formulen observaciones, mejoras o pretensiones morales alternativas con la finalidad de que sean acogidas para sustituir o mejorar las vigentes — por ejemplo, la crítica contra la pena de muerte en aquellos países donde exista acuerdo social sobre su aplicación-. En esos casos, las propuestas de tipo moral reciben el nombre de moral crítica. Esta corresponde a lo que José Luis L. Aranguren denomina «moral como actitud», pues «es siempre de exigencia y de autoexigencia, de sed de justicia, de búsqueda e inquietud, de inconformismo y crítica del código moral vigente que, por perfecto que parezca es siempre perfectible, y de propuesta, a veces sólo balbuciente, de un orden moral mejor». ${ }^{5}$

Finalmente, cuando una moral se corresponde con el proyecto de la Modernidad y de la Ilustración, suele recibir el nombre de moral ilustrada. ${ }^{6}$ Este proyecto no coincide exactamente con un período de tiempo, como el de la Edad Moderna, sino con un programa cultural y un espíritu crítico que, originados en ella — con antecedentes en el Tránsito a la Modernidad, que en algunos casos hunde sus raíces en la Antigüedad—, se proyectan hasta la actualidad. ${ }^{7}$ Tiene como ideales,

3 Véase Díaz, Elías. Curso de Filosofía del Derecho. Madrid: Marcial Pons, Ediciones Jurídicas y Sociales, 1998, p. 43.

4 Confróntese Fernández, Eusebio. «Sobre la ética y su justificación». En Estudios de ética jurídica. Madrid: Debate, 1990, pp. 101-102.

5 Aranguren, José Luis. Ética de la felicidad y otros lenguajes. Madrid: Tecnos, 1988, p. 106.

6 Es el sentido con el que Gregorio Peces-Barba utiliza la palabra «ilustrada» en su Curso de Derechos Fundamentales, teoría general (1995), con la colaboración de Rafael de Asís, Rafael Fernández Liesa y Ángel Llamas Gascón. Madrid: Universidad Carlos III de Madrid, Boletín Oficial del Estado, reimpresión de 1999, pp. 231 (al final), 236 (penúltimo párrafo) y 290 (primer párrafo).

7 Por «Tránsito a la Modernidad» se entiende, de manera general, aquel periodo que va entre la Edad Media y la Edad Moderna, durante el que muchas de las estructuras, económicas, sociales, políticas y culturales desaparecen, aunque otras se adaptan a la nueva era. No se trata de una etapa histórica con un principio y 
en el plano filosófico, a la racionalidad, la dignidad del ser humano, la emancipación del individuo y el cosmopolitismo, y, en el plano jurídicopolítico, a los valores de libertad, igualdad, solidaridad y seguridad. ${ }^{8}$

Los ámbitos de la vida humana que son objeto de la moral también suelen ser materia de clasificación. Esta responde al común convencimiento de las teorías éticas contemporáneas «de que la felicidad y la justicia no son lo mismo».9 Se distingue así el ámbito de la felicidad, del bien, la virtud, la salvación y, en general, del plan de vida de las personas; del ámbito de la justicia de las relaciones humanas, de la manera como debe organizarse la sociedad para que sus estructuras e instituciones — sean políticas, jurídicas, económicas, culturales, entre otras- sean justas. Dos ámbitos de la moral que, por las diversas posibilidades que presentan, deben tomarse en sentido abierto y flexible. Aunque resulten diferentes, ejercen entre sí una influencia recíproca, tanto para favorecer su realización como para dificultarla - por ejemplo, un orden social injusto es proclive a obstaculizar los proyectos vitales de las personas, mientras que un comportamiento virtuoso alienta la justicia en las relaciones humanas-.

La filosofía moral —o ética propiamente dicha - se ocupa de los problemas relacionados con la moral en un plano general y abstracto. No estudia una moral determinada - sea de tipo personal, social o crítica-, sino lo moral en su especificidad: examina las condiciones que debe reunir una acción humana para ser definida justificadamente como moralmente válida — esto es: buena o justa—. Al ser aquel su objeto, no construye en estricto la moral (esa labor está reservada a la conciencia moral autónoma del individuo); tan solo se ocupa de ella. A diferencia de esta última, no se ocupa de resolver problemas morales concretos, ni de prescribir cómo deberían comportarse los individuos; tan solo de reflexionar, de forma sistemática y metódica, sobre la validez, sentido y fundamentación de las prescripciones morales, con el propósito de que los seres humanos crezcan en saber acerca de sí mismos, sean más dueños de sí y se perfeccionen en libertad. Por esa razón, no puede ni debe ser moralmente aséptica: si bien no orienta los comportamientos humanos de modo inmediato, sí lo hace de manera mediata a través de la reflexión filosófica sobre la que constituye su objeto de estudio. ${ }^{10}$ Puede clasificarse a su vez en ética descriptiva y ética normativa. ${ }^{11}$

8 Sobre cómo fue gestándose este proyecto cultural y los aportes que recibió, véase FASSÓ, Guido. Historia de la filosofía del Derecho, la Edad Moderna. Traducción de José F. Lorca Navarrete. Madrid: Ediciones Pirámide, 1982 [1966], volumen II de la obra general.

9 Camps, Victoria. Ética, retórica, política. Madrid: Alianza Universidad, 1988, p. 119.

10 Véase Cortina, Adela. Ética mínima. Introducción a la filosofía práctica. Novena edición. Madrid: Tecnos, 2004 [1986], pp. 27-32.

11 Confróntese, sobre la clasificación de la ética, PIEPER, Annemarie. Ética ymoral. Una introducción a la filosofía práctica. Traducción de Gustau Muñoz. Barcelona: Editorial Crítica, 1991 [1985], pp. 189-195.

LA EDIFICACIÓN DE LA MORAL RELEVANTE PARA LA POLÍTICA Y EL DERECHO 
La ética descriptiva agrupa a todas aquellas teorías que se ocupan esencialmente de explicar, interpretar y analizar la actividad humana como un dato empírico e histórico, con el propósito de clarificar la relevancia de lo moral a partir del contexto de la acción. Destaca dentro de ella la ética de los valores, cuyo enfoque fenomenológico describe y analiza los datos de una conciencia moral para, a partir de ella, elaborar una doctrina de los valores morales, establecer su prelación y las normas que se basan en ese orden.

La ética normativa agrupa a todas las teorías que se ocupan de manera principal en fundamentar los principios o normas morales, mediante el desarrollo de criterios para generarlas o examinarlas, sea a través de un principio moral superior que se considere aplicable de manera incondicional, o a través de un bien superior cuya realización se considere vinculante para todos. Dentro de ella se encuentran, entre otras, las éticas deontológicas y las éticas constructivistas.

Las éticas deontológicas se sustentan sobre un principio básico que orienta y delimita la libertad de elección hacia la consecución de una finalidad trascendente, como la dignidad o autonomía moral, y hacen de de esta una ley de la voluntad. Suelen hacer uso de una racionalidad monológica para derivar las normas válidas moralmente (es el caso de la filosofía moral kantiana).

Las éticas constructivistas parten de un principio moral superior con el cual instituyen un procedimiento para fundamentar, generar y examinar las normas morales, así como solucionar de manera pacífica los conflictos, a través de los medios que proporciona la racionalidad práctica y la comunicación racional (es lo que ocurre con las éticas contractualistas y las éticas comunicativas). Su idea central es que los juicios morales se justifican sobre la base de presupuestos procedimentales, y tal vez aun sustantivos, de la práctica social de la discusión moral en cuyo contexto se formulan.

Uno de los temas más difíciles y controvertidos de abordar es la determinación de aquello que es moral o inmoral, de definir cuándo un comportamiento es moralmente bueno o malo, justo o injusto. Probablemente existan tantas posturas como filósofos o teóricos han abordado el tema, con importantes y razonables puntos de vista, que hacen sumamente difícil brindar una única respuesta correcta. Esto se debe en buena medida a que su determinación implica un juicio de valor; por tanto, se encuentra sometida a diversos factores que rodean o inciden en la persona que efectúa la valoración. También a que son innumerables los diferentes casos concretos que se pueden presentar, por lo que brindar una única respuesta correcta es una labor hercúlea o imposible de realizar.

Son dos los problemas filosóficos fundamentales que están detrás de la pregunta sobre qué es moralmente válido. Si queremos que la reflexión moral tenga dosis suficientes de racionalidad, esos problemas deben ser 
razonablemente abordados. El primero consiste en verificar si existen criterios o procedimientos racionales para justificar la validez de los juicios de valor; es decir, si hay algún modo de demostrar que un juicio moral es válido de tal forma que esa demostración sea, en principio, asequible a cualquier persona normal que estuviera en las condiciones adecuadas. El segundo consiste en determinar cuáles son los valores o principios que permiten enjuiciar los comportamientos humanos desde un punto de vista moral, así como determinar sus implicaciones sobre materias específicas. ${ }^{12}$

En este trabajo nos referiremos a dos de las teorías éticas normativas que han intentado responder al primero de los problemas planteados. Nos referiremos específicamente a los criterios o procedimientos racionales para edificar una moralidad relevante vinculada con la política y el Derecho. La elección de ambas teorías se debe a que han resultado especialmente significativas en la construcción y el fortalecimiento de las sociedades democráticas modernas. La primera corresponde a las éticas deontológicas y la segunda a las éticas constructivistas, en ambos casos de raíz kantiana. Sin embargo, no debe perderse de vista que otras concepciones son teóricamente posibles y de hecho existen — como las teorías contractualistas y las utilitaristas-. La adopción de una u otra concepción será siempre un acto de elección, una toma de posición - expresa o tácita - sobre cuál ha de ser el camino y la perspectiva a seguir. Razones pueden haber muchas: la finalidad perseguida, las ventajas comparativas, su utilidad para lograr un conocimiento integral del objeto que se estudia, hasta la posición ideológica que subyace al pensamiento del autor. Aquí nos limitaremos a examinar aquellas dos.

El segundo problema no será abordado en este trabajo para no exceder la extensión que le ha sido asignada. Simplemente señalaremos que, en las sociedades afines al proyecto ilustrado y moderno, esos valores suelen ser el de libertad, igualdad, solidaridad y seguridad.

\section{II.LAS ÉTICAS DEONTOLÓGICAS DE RAÍZ KANTIANA: EL EQUILIBRIO ENTRE LOS PRINCIPIOS DE AUTONOMÍA Y UNIVERSALIDAD, ORIENTADOS POR LA DIGNIDAD HUMANA}

Las éticas que pertenecen a este grupo parten de un postulado humanista antropocéntrico: la eminente dignidad de la persona. Con ese presupuesto postulan una moral humanista, ilustrada, que actúa sobre la política y el Derecho, y que los orienta, presiona y critica, a fin de construir o fortalecer una sociedad libre, abierta, plural y democrática, donde cada ser humano pueda alcanzar con su esfuerzo, pero con el apoyo de los demás, su autonomía moral, el desarrollo integral de todas las dimensiones de

LA EDIFICACIÓN

DE LA MORAL

RELEVANTE PARA LA POLÍTICA Y EL DERECHO 
su humanidad. Una propuesta de un orden moral que responde a una ética normativa que, aunque cuenta con vocación de universalidad, está especialmente dirigida a las sociedades que han asumido el proyecto de la Ilustración y de la Modernidad o que pretenden hacerlo. En ella, la dignidad del ser humano aparece ubicada racionalmente como su fundamento y fin último — al igual que de la política y del Derecho-; y el dinamismo de la libertad como el iter de su recorrido; es decir, tiene como punto de partida a la libertad de elección y como meta a la libertad autonomía: el desarrollo integral de la persona.

La libertad de elección se refiere aquí única y exclusivamente a nuestra capacidad psicológica para elegir. Es un punto de partida para reflexionar y realizar la condición humana. No se refiere todavía a los condicionamientos y factores que influyen en esa posibilidad de elección, ni a las necesidades humanas que deben ser satisfechas para que el ser humano pueda estar en condiciones reales e iguales de elegir. Significa que, a pesar de sus condicionamientos históricos, económicos, culturales, etcétera, por más difíciles que sean sus circunstancias, el ser humano siempre podrá elegir: optar por uno u otro camino, decidir entre lo bueno o lo malo, lo justo o lo injusto, aceptar una proposición o negarse a ella, aun cuando tenga que afrontar las consecuencias de sus propias decisiones. Es importante porque sobre la base de ella el ser humano toma decisiones vinculadas con su propia individualidad, pero también porque las toma con relación a los demás y en las diversas situaciones de la vida social e histórica. «Esta libertad inicial es un presupuesto de la moralidad. Sin ella no se podrá hablar en términos éticos». ${ }^{13}$

A partir de la libertad de elección, el hombre y la mujer, que pretendan actuar con coherencia a su condición de persona, orientan cotidianamente sus decisiones y actuaciones hacia su libertad autonomía, es decir, a alcanzar el máximo desarrollo posible de todas las dimensiones de su humanidad: el desarrollo integral de la persona. Este tipo de libertad, llamada también «libertad moral» o «autonomía moral», exige del ser humano un esfuerzo constante — con sus errores y tropiezos, pero también con su decisión y fortaleza- para ser dueño de sí mismo, gobernante de su propia vida, para alcanzar la plenitud de su humanidad, al hacer uso correcto de su libertad de elección, al desprenderse y al superar los obstáculos y condicionamientos que se encuentran en su propia vida, así como en la vida social, que impiden o dificultan su autenticidad y el desarrollo de todas las dimensiones de su ser. Exige también que no sea egoísta, ni indiferente con la suerte de los demás, sino, por el contrario, que coopere con el bienestar de los otros, en una mutua responsabilidad y solidaridad que tenga como objetivo final la humanización de todos y cada uno de los miembros de la familia humana. Solo así se puede trabajar seria y cabalmente para alcanzar el desarrollo integral, pues este

13 Peces-Barba, Gregorio. «Nuevas reflexiones sobre la teoría democrática de la justicia -los derechos fundamentales entre la moral y la política一». En Escritos sobre derechos fundamentales. Madrid: Ediciones de la Universidad Complutense, 1988, p. 221. 
es imposible de alcanzar en solitario. Exige además cuidar el resto de la naturaleza porque no se puede alcanzar un desarrollo humano, real y vivificador prescindiendo de ella. Debido a su alto nivel de exigencia, "[l]a libertad moral o de autonomía moral es una meta, un fin, un ideal a alcanzar, quizás la utopía de la condición humana». ${ }^{14}$ Un proyecto difícil pero posible, conocido también — por esa razón - como «libertad final»: el estado en que el ser humano logra su autonomía moral, el máximo grado de realización de todas las dimensiones que constituyen su humanidad. Así, mientras la libertad de elección es un rasgo que ya le viene dado a cada sujeto moral, la autonomía moral es un rasgo, una meta, que debe construirse día a día con la interacción y la cooperación social.

Estos dos sentidos de libertad se comunican entre sí y solo pueden ser cabalmente entendidos si se los estudia de manera vinculada. Ambos integran el dinamismo de la libertad, que va desde la libertad de elección hacia la libertad de autonomía. ${ }^{15}$ Una dinámica relación donde ambos extremos se necesitan y condicionan recíprocamente:

Así, la libertad de elección es la base de la libertad moral. Sólo podemos hablar de libertad moral porque existe libertad de elección, y la libertad de elección sólo es consecuente cuando actúa para alcanzar unos fines, es decir, si existe la libertad moral como objetivo. Ambas son necesarias y prescindir de una, deteriora o destruye el sentido de la otra. La libertad de elección es condición de la libertad moral, y la libertad moral meta de la libertad de elección. ${ }^{16}$

Sobre esa base, estas éticas deontológicas postulan una moral situada en el dinamismo de la libertad: aquella que parte de la libertad de elección y se orienta hacia la libertad autonomía, para procurar el desarrollo integral de todas las dimensiones del ser humano.

Una postura de evidente raíz kantiana, pues vincula la idea de dignidad con la libertad, la autonomía y la moral. En efecto, para Kant todo ser humano es libre para autodeterminarse racionalmente en el plano moral, independientemente de las causas externas que incidan sobre él (libertad de elección).$^{17}$ Esto implica que el individuo puede crear o asumir libremente, sin interferencias de tipo alguno, su propio plan de vida, sus propias normas para regir su destino y alcanzar su emancipación o desarrollo integral (autonomía moral). Al ser capaz de tal actuación, el ser humano es un ser de fines, un sujeto que no tiene precio, que «existe como un fin en sí mismo, no simplemente como un medio para ser utilizado discrecionalmente por esta o aquella voluntad»; por esa razón, en todas

LA EDIFICACIÓN

DE LA MORAL

RELEVANTE PARA LA POLITICA Y EL DERECHO 
sus acciones, «tanto en las acciones orientadas hacia sí mismo como en las dirigidas hacia otros seres racionales el hombre ha de ser considerado siempre al mismo tiempo como un fin», nunca como simple medio, ni mucho menos como objeto (dignidad). ${ }^{18}$ Para asegurar ese propósito, las acciones o decisiones que se adopten deben considerar siempre la igual dignidad que corresponde a todos los miembros de la familia humana. No podría defenderse la dignidad de uno y negársela a los demás. Por lo tanto, para que las acciones o decisiones sean moralmente válidas — según el pensamiento kantiano- no solo deben ser producto de la libertad de elección y del uso autónomo de la razón, sino también ser imparciales, no egoístas ni utilitaristas, sino susceptibles de ser elevadas a ley general. Son exigencias propias de los principios de autonomía y universalidad, que se derivan racionalmente de la dignidad humana y se encuentran orientados por ella. Dos principios éticos procedimentales, pues, a diferencia de los materiales, no nos dicen qué es lo moralmente correcto en cada caso; tan solo nos indican las pautas que deben seguirse para determinarlo.

Según el principio de autonomía, toda conducta, criterio, norma o decisión que aspire a ser considerada como moral no debe ser impuesta. El ser humano debe tener libertad para autodeterminarse racionalmente; de lo contrario, se vulneraría su eminente dignidad. Lejos de ser tratado como un fin, sería tratado como un simple objeto. Estamos ante uno de los presupuestos de la moral ya que sin libertad de elección no puede hablarse en términos éticos. Por esa razón, en cualquiera de sus clasificaciones o sentidos, la moral requiere de la libre elección de la persona. El papel que juega en ella el individuo es imprescindible, e irremplazable el lugar que ocupa su conciencia moral para elegir libremente y de forma responsable. Incluso la moral social no puede ser impuesta. A esta le sigue el examen, la aceptación o el rechazo individual. La moral debe originarse fundamentalmente en la conciencia moral del individuo o no será moral. ${ }^{19}$

El principio de universalidad exige que toda conducta, criterio, norma o decisión que pretenda ser considerada como moral no sea el producto de un subjetivismo ético, de un simple capricho o arbitrariedad, sino una elección adoptada por la razón y susceptible de ser elevada a ley general; es decir, que todos puedan quererla igualmente porque satisface intereses universalizables. Kant lo expresa de esta manera: «obra según aquella máxima por la cual puedas querer que al mismo tiempo se convierta en una ley universal»; o dicho de otra forma: «obra como si la máxima de tu acción pudiera convertirse por tu voluntad en una ley universal de la naturaleza».20

18 Ibid., p. 114, ambas citas. La cursiva no es mía.

19 Como señala Eusebio Fernández: «La conciencia moral de cada uno obra con total libertad y autonomía, tanto si decide observar la moral vigente en su sociedad como si decide poner en cuestión o desdeñar las normas y valores morales establecidos. El que acepta, observa, pone en cuestión o rechaza determinados modelos deconductamoraleselhombreensumásestrictaindividualidady,comotal,nopuedetransferirla responsabilidad de su opción a nadie.» En «Sobre la ética y su justificación». Op. cit., p. 102.

20 Fundamentación para una metafísica de las costumbres. Op. cit., p. 104, ambas citas. La cursiva no es mía. 
Para lograr ese propósito, las normas morales deben ser determinadas con imparcialidad de modo tal que lo prescrito logre un reconocimiento universal. Como explica Ernst Tugendhat, la imparcialidad supone tomar una decisión «que tenga igualmente en cuenta a todos», requiere que nos pongamos mentalmente «—de forma hipotética — en [el] lugar de todos los demás». ${ }^{21}$ Con tal planteamiento se excluyen las concepciones éticas egoístas y utilitaristas. No sería posible una moral calculada, sea a favor de la mayoría o del individuo que la esgrime, sino que los principios morales deben estar siempre presentes aunque no produzcan beneficios en un caso concreto. Tampoco sería moral un planteamiento dirigido a obstaculizar o impedir el desarrollo integral de la persona o que la someta a una situación de indignidad. De esta manera, se pretende evitar que unos se beneficien indebidamente a costa de los demás y, en general, garantizar que las normas o elecciones sean compatibles con la igual dignidad que corresponde a todas las personas. La asunción de este principio hace que el punto de vista moral sea una operación de universalización de las máximas y los intereses controvertidos en el que las partes valoran imparcialmente los intereses de todos, que trasciendan el contexto social o cultural en el que se encuentren y las circunstancias contingentes que puedan existir, a fin de adoptar una decisión moralmente válida susceptible de ser aceptada por todos. ${ }^{22}$ Un camino epistemológico que se aparta de los particularismos y relativismos, y que se diferencia del punto de vista político y jurídico porque las normas o decisiones, para ser válidas en estos órdenes, no necesitan cumplir con las exigencias de la universalidad, sino con los criterios de conveniencia y juridicidad, respectivamente.

Resulta importante insistir en que los principios de autonomía y universalidad, tal como se encuentran definidos en el sistema moral kantiano, se encuentran orientados siempre por la eminente dignidad de la persona. Esta se presenta racionalmente como su fundamento y como la meta última que persiguen, como el principal referente que delimita sus exigencias y permite establecer su significado práctico. El propio Kant lo expresa de esta manera:

[S]i debe darse un supremo principio práctico y un imperativo categórico con respecto a la voluntad humana, ha de ser tal porque la representación de lo que supone un fin para cualquiera por suponer un fin en sí mismo constituye un principio objetivo de la voluntad y, por lo tanto, puede servir como ley práctica universal. [...]. El imperativo práctico será por lo tanto éste: Obra [sic] de tal modo que uses a la humanidad, tanto en tu persona como en la persona de cualquier otro, siempre al mismo tiempo como fin y nunca simplemente como medio. ${ }^{23}$ 
Para Kant, este «principio [de humanidad...] es en el fondo idéntico a éste: "Obra según una máxima que contenga dentro de sí a la vez su propia validez universal para todo ser racional"». ${ }^{24}$ Se desprende así que la idea de dignidad humana es pieza imprescindible para la correcta comprensión del principio de universalidad, como lo es también para el principio de autonomía, por cuanto proporciona los parámetros sin los cuales no es posible establecer satisfactoriamente el significado práctico de cada uno de ellos, ni las exigencias que se desprenden de sí como criterios de tipo moral. No son, entonces, los principios de autonomía y universalidad los que establecen el contenido de la dignidad humana, sino es esta última la que establece el significado normativo de cada uno de ellos. ${ }^{25}$ Lo reitera el propio autor alemán:

Pues decir que debo restringir mi máxima en el uso de los medios hacia todo fin a la condición de su universalidad como ley para todo sujeto, equivale a decir que el sujeto de los fines, o sea, el propio ser racional, tiene que ser colocado como fundamento de todas las máximas de las acciones nunca simplemente como medio, sino como suprema condición restrictiva en el uso de todos los medios, es decir, siempre y simultáneamente como fin. ${ }^{26}$

Al ubicar a la dignidad de la persona como el fundamento y fin último de la moral, las éticas humanistas de corte kantiano constituyen a la dignidad en el principal referente para orientar y delimitar los discursos y preceptos morales - también los políticos y jurídicos—, para valorar la corrección de cualquier pretensión, postura o actuación, para sustentar una serie de exigencias en beneficio de la condición humana (como las que corresponden a los principios de autonomía y universalidad). Por esa razón, la libertad de elección a la que esta concepción se refiere no es - ni puede ser- una libertad sin referente ético. Si bien ella permite a todo individuo, dotado de razón y de voluntad, autodeterminarse racionalmente para regir su propio comportamiento —más allá de los condicionamientos externos que puedan presentarse-, no es una libertad que pueda ejercitarse en contra de la dignidad de la persona. $\mathrm{Si}$ la libertad de elección es uno de los rasgos que caracteriza la condición humana, uno de los fundamentos de su eminente dignidad, entonces no puede dar lugar — válidamente— a una elección contraria a aquella condición, a la eminente dignidad que le corresponde. Antes bien, debe orientarse a maximizar todas sus dimensiones, a alcanzar la libertad moral, su desarrollo integral. Como consecuencia de ello, no toda elección vale, o vale lo mismo, desde esta perspectiva moral. La dignidad del ser humano y, como expresión de ella, el dinamismo de la libertad encauzan la elección para que pueda ser moralmente correcta. Esta conclusión vale tanto para las elecciones que el ser humano adopte respecto de sí 
mismo, como para las que adopte en relación con los demás. Por eso sus decisiones, para ser moralmente válidas, además de no ser impuestas, deben tener una vocación de universalidad orientada por la eminente dignidad de la persona. La explicación se encuentra en la misma idea de dignidad: esta reclama ser recíprocamente reconocida entre todos los seres humanos, pues no sería posible reclamar el reconocimiento de la dignidad de uno y negársela a los demás.

La moral que esta concepción postula tiene como requisito el equilibrio entre el principio de autonomía y el de universalidad, orientados siempre hacia el desarrollo integral de la persona. Se trata de dos principios éticos procedimentales que constituyen, para estas teorías, los criterios básicos para fundamentar la validez moral de los enunciados y juicios morales, para generar normas morales válidas y evaluar las existentes, así como para resolver los problemas morales concretos o los conflictos de acción que puedan presentarse.

$\mathrm{Al}$ asumir como postura el equilibrio entre los principios de autonomía y universalidad, descartan tanto las éticas que se centran exclusivamente en el principio de universalización como aquellas que se basan únicamente sobre el principio de autonomía.

Las éticas que prescinden del principio de autonomía son aquellas que pretenden una aceptación casi automática de sus postulados, por parte de las personas a las que se dirigen. Son éticas autoritarias que pretenden imponer sus contenidos y que diseñan los planes de vida de las personas al margen de su voluntad. En ellas, el dinamismo de la libertad desaparece, pues el individuo ya no puede elegir: se prescinde de su libertad, de su autonomía como aceptación responsable de su moralidad. Son éticas incompatibles con cualquier otra cosa que no consideren verdaderas, rechazan el pluralismo y son propias de sociedades cerradas. Suelen ser éticas fundamentalistas, integristas y totalitarias.

Las éticas que prescinden del principio de universalidad parten por considerar que es imposible que se puedan ofrecer propuestas morales a ser consideradas o aceptadas por todos. Son éticas relativistas que se basan sobre la subjetividad o los particularismos. Suelen complacerse en el aislamiento, tanto en la sociedad como en la política, y favorecen el retiro hacia el ámbito grupal o a la privacidad sin abrirse al encuentro con los demás.

La moral que defienden las éticas humanistas de raíz kantiana rechaza esos dos reduccionismos. Al ser una moral que se inserta dentro de la Modernidad, integra tanto el principio de autonomía como el de universalidad en una relación de complementariedad. 


\section{LAS ÉTICAS COMUNICATIVAS DE RAÍZ KANTIANA: UNA CONCEPCIÓN CONSTRUCTIVISTA REGIDA POR EL PRINCIPIO DISCURSIVO DE UNIVERSALIZACIÓN Y EL DE ADECUACIÓN}

Las éticas comunicativas, llamadas también «dialógicas» o «discursivas», son cierto tipo de filosofía moral basada sobre el consenso. Si bien presentan variedades, todas ellas se contraponen al paradigma del pensador solitario que accede a la verdad a través de criterios de claridad y distinción manifestados en una conciencia encerrada en sí misma, es decir, que no se encuentra abierta al diálogo con los demás. Parten de afirmar el carácter dialógico de la razón humana, sustentada en el hecho de que los seres humanos realizamos acciones comunicativas, de que los seres humanos argumentamos. Por esa razón, para ellas el discurso moral no puede ser monológico; por el contrario, es necesariamente intersubjetivo y cooperativo: requiere de la participación de todos los potencialmente afectados o, por lo menos, que todos los que quieran participar tengan la posibilidad de hacerlo. Solo la participación puede evitar una interpretación equivocada de las posturas de cada quien por parte de los demás. Como consecuencia de ello, este tipo de ética considera necesario incrementar la participación de los individuos en la construcción de la moralidad, de todos los potencialmente afectados, a fin de que la imparcialidad o universalidad moral no se construya desde una reflexión individual, sino desde una reflexión colectiva y cooperativa. ${ }^{27}$

Dos de los autores más representativos de la teoría ética comunicativa, que presentan además una evidente raíz kantiana, son Karl-Otto Apel y Jürgen Habermas. Sus aportes han contribuido de manera significativa a la filosofía moral y política de nuestro tiempo. Si bien existen disensiones en sus planteamientos, en lo que se expresa aquí se muestran básicamente de acuerdo. Sus planteamientos han experimentado evoluciones a lo largo del tiempo. Aquí describiremos sus postulados básicos, específicamente el procedimiento que utilizan para fundamentar y generar enunciados y juicios morales.

Las éticas comunicativas que formulan no se ocupan de la totalidad de las cuestiones prácticas, sino de las que resultan accesibles a una discusión racional y a una posterior fundamentación. Nos brindan un

27 En los años setenta del siglo XX, nace en Frankfurt, de la mano de Karl Otto Apel y Jürgen Habermas, una filosofía moral que: "se da a sí misma el nombre de "ética comunicativa" o "ética discursiva", porque reconstruye el imperativo kantiano con medios de la teoría de la comunicación". Si en la época griega y la medieval, la filosofía hace del ser su centro de atención, y en la Modernidad este es desplazado por la conciencia como principal objeto de reflexión; en la actualidad la filosofía moral centra su interés en el lenguaje,contempladotantoensudimensiónsintácticaysemánticacomoensudimensión pragmática,yse atiende a los sujetos que hacen uso de él. «El punto de partida de la reflexión filosófica será ahora la acción comunicativa, que hace posible la producción y reproducción del mundo de la vida, y a través de ella llegamos a descubrir el carácter dialógico de la razón humana, de esa razón que es en diálogo, no en monólogo." Por ello, «[]a búsqueda de la verdad teórica y de la corrección de las normas prácticas, meta de los saberes teórico y práctico, es ahora una tarea dialógica y, por tanto, comunitaria; una tarea que, para llevarse a cabo, precisa contar en el terreno de la ética, en el ámbito preocupado por la corrección de las normas prácticas, con la aceptación de todos los afectados por ellas, tras un diálogo celebrado en condiciones de simetría». Apel, Karl-Otto, Adela, Cortina y otros. «Prólogo». En K.O. Apel, A.Cortina, J. DeZan y D. Michelini (editores). Ética comunicativa y democracia. Barcelona: Crítica, 1991, p. 7. La cursiva no es mía. 
procedimiento que sirve para reflexionar y discutir, desde el punto de vista moral, sobre la justicia de las relaciones humanas, sobre la manera de edificar la estructura básica de la sociedad. ${ }^{28}$

Para realizar esa labor tienen en cuenta una constatación: las sociedades con cierto grado de complejidad - como ocurre con las sociedades modernas - carecen de una unidad axiológicamente homogénea. Son sociedades plurales en las que concurren diferentes concepciones del bien — de la felicidad, la vida buena o virtuosa, de la salvación-. Por eso, la posibilidad de encontrar principios absolutos e incontrovertibles resulta difícil, si no imposible. Eso no quita la necesidad de encontrar normas, susceptibles de ser aceptadas por todos, que regulen la manera como debe instituirse y mantenerse un orden justo de convivencia — una concepción de justicia-. Ante este panorama, la ética discursiva se muestra recelosa de encontrar una concepción del bien que pueda ser compartida por todos. Para ella, esta es una cuestión privada que corresponde a cada persona determinar, por lo que no debe formar parte de una reflexión moral que tenga por objeto establecer las normas morales, de alcance intersubjetivo, que contribuyan a organizar la sociedad. Su elaboración teórica y su desarrollo práctico dejan de lado las cuestiones evaluativas referentes a las concepciones del bien — por considerar que corresponde a lo más íntimo de la personalidad de cada individuo-, para centrar su interés a las cuestiones normativas referentes a la justicia del orden social —a la estructura básica de la sociedad-. ${ }^{29}$ Una distinción que, en palabras de uno de sus exponentes, intenta «defender la primacía de lo justo entendido deontológicamente sobre lo bueno», ${ }^{30}$ por lo menos «en el sentido de que "lo justo" limita qué preceptos pueden considerarse pertenecientes a un comportamiento virtuoso», al punto de que «las concepciones de "lo bueno" queden constreñidas por las nociones de "lo justo"». ${ }^{31}$

Ese mismo panorama hace que esta concepción rechace la previa existencia de principios éticos sustantivos que permitan determinar, de manera absoluta y definitiva, lo que es o no es moralmente correcto en cada caso. Su enfoque corresponde a las éticas constructivistas, pues en el punto de partida de su reflexión moral solo existen

28 Confróntese Habermas, Jürgen. «Ética del discurso. Notas sobre un programa de fundamentación». En conciencia moralyacción comunicativa. Traducción de Ramón García Cotarelo. Barcelona: Península, 1985, p. 129. Y, del mismo autor, El futuro de la naturaleza humana. Barcelona: Paidós, 2002, pp. 13-14.

29 Véase Habermas, Jürgen. El futuro de la naturaleza humana. Op. cit., pp. 11-28. También del mismo autor Verdad y justificación. Madrid: Trotta, 2002, pp. 291-292; y «Ética del discurso. Notas sobre un programa de fundamentación". Op. cit., pp. 129 y 134. La distinción entre las cuestiones evaluativas referentes a la vida buena y las cuestiones normativas referidas a la justicia ha servido a Habermas para diferenciar entre ética y moral. Según su teoría, la ética se ocupa de las cuestiones relativas a la vida buena y la moral a las cuestiones relativas a la justicia. Mientras laética responde al punto de vista de lo que es buenoen «interés de uno" - sea que este «uno" se refiera a una persona o a un grupo de personas-, la moral responde al punto de vista de lo quees bueno «paratodos» (universalidad). Finalmente, mientras la fuerza prescriptiva de laética depende del contexto social, la moral aspira al reconocimiento universal (confróntese su obra $E I$ futuro de la naturaleza humana. Op. cit., pp. 13-14; también su trabajo «Del uso pragmático, ético y moral de la razón práctica». Op. cit., pp. 109-126).

30 Habermas, Jürgen. «Prólogo». En Aclaraciones a la ética del discurso. Madrid: Trotta, 2000, p. 9.

31 Velasco, Juan Carlos. Para leer a Habermas. Madrid: Alianza Editorial, 2003, p. 62, las dos últimas citas.

LA EDIFICACIÓN DE LA MORAL RELEVANTE PARA LA POLÍTICA Y EL DERECHO 
principios éticos procedimentales que nos indican las pautas que deben seguirse para fundamentar los enunciados y juicios morales. Solo a través de estas pautas los sujetos podrán establecer los principios éticos de contenido sustantivo que acompañarán, necesariamente, a los principios éticos procedimentales — por ejemplo, los valores de libertad, igualdad y solidaridad - ${ }^{32}$ La ausencia de esos principios sustantivos intensifica la exigencia de la participación responsable de las personas, pues de ellas depende la decisión que se adopte sobre la corrección moral de las normas, así como la garantía de que estas sean respetuosas de todos y cada uno de los seres humanos.

Tras esa constatación y toma de posición, la ética discursiva se orienta a brindarnos un procedimiento intersubjetivo que, de manera principal, permita fundamentar la validez de nuestros enunciados y juicios morales -moralidad referida a las cuestiones de justicia, no a las cuestiones del bien, como la vida buena o felicidad-. Solo de manera derivada sirve también para la resolución de conflictos de acción a través de medios comunicativos orientados a alcanzar el consenso. Esta extensión argumentativa de la acción comunicativa permite aplicar este procedimiento a la generación de normas morales válidas y a la evaluación de las existentes. Para tal efecto, se concibe la tarea de fundamentación moral como algo cercano a los discursos reales entre seres humanos, por lo que se postula que la validez de una norma moral debe ser comprobada en las argumentaciones e interpretaciones fácticas. ${ }^{33}$

En efecto, para la ética discursiva, ningún sujeto moral puede decidir, con independencia del resto, qué norma es moralmente correcta cuando se trata de la justicia de las relaciones humanas - no cuando se trata de cuestiones referentes a las concepciones del bien, pues su validez moral dependerá exclusivamente de la conciencia individual de las personas, aunque se encuentre influenciada por el contexto socialTal decisión se tiene que adoptar por consenso mediante un diálogo entre todos los sujetos que resulten potencialmente afectados y que se caracteriza por satisfacer — por lo menos de modo aproximado- las condiciones de racionalidad propias de una «situación ideal de habla» — llamada también «situación ideal de diálogo» o «comunidad ideal de comunicación»—. ${ }^{34}$ Esta es una situación hipotética, ideal, en la que los participantes se orientan hacia el reconocimiento intersubjetivo, en

32 «[Y]a no podemos fundamentar(y, por tanto, prescribir)a priori [es decir, de manera previa la experiencia decomunicación]determinadasnormasinstitucionalesdelaeticidadsustancialenelsentidohegeliano,ni determinadasdefinicionesdelavidaperfecta,nitampocodelamayorfelicidadposibledetodoslosindividuos, sino solamente de una forma procedimental de deliberación y decisión sobre tales cuestiones sustanciales". APEL, Karl-Otto. “¿Límites de la ética discursiva?». En Adela Cortina. Razón comunicativa y responsabilidad solidaria. Salamanca: Sígueme, 1985, p. 249.

33 Véase HaBERmAS, Jürgen. «Ética del discurso. Notas sobre un programa de fundamentación». Op. cit.,pp. 77 y 88-97.

34 «Llamo ideal a una situación de habla en que las comunicaciones no solo no vienen impedidas por influjos externos contingentes, sino tampoco por las coacciones que se siguen de la propia estructura de la comunicación. La situación ideal de habla excluye las distorsiones sistemáticas de la comunicación. Y la estructurade lacomunicación dejadegenerarcoacciones solosi paratodoparticipanteeneldiscursoestá dadaunadistribución simétricadelasoportunidadesdeelegiryejecutaractosdehabla». HABERMAS, Jürgen. Teoría de la acción comunicativa: complementos y estudios previos. Madrid: Cátedra, 1989, p. 153. 
la búsqueda de un consenso que se logra de forma intersubjetiva y en la que cada quien formula pretensiones de validez moral con disposición a problematizarlas y a problematizar las pretensiones de los otros sujetos, sobre una base dialógica; y donde la deliberación ha de cumplir con aproximación suficiente las siguientes condiciones: «a) [Que] se escuchen todas las voces relevantes; b) [que] puedan hacerse valer los mejores de todos los argumentos disponibles habida cuenta del estado presente de nuestro saber, y c) [que] sólo la coerción sin coerciones que ejercen los buenos argumentos determine las posturas de afirmación o negación de los participantes». ${ }^{35}$

En ese escenario ideal, los sujetos tienen libertad, tanto para formular pretensiones de racionalidad con cada acción comunicativa, como para rechazar las pretensiones elevadas por otros interlocutores. Una vez más, el fundamento puede encontrarse en el igual valor moral que les corresponde por su condición de personas. Cada sujeto potencialmente afectado es un interlocutor válido que debe ser tenido en cuenta al momento de decidir qué normas le afectan. Si se tomara una decisión sin tener en cuenta a todos los potencialmente afectados, tal decisión sería inmoral. Los potencialmente afectados no son solo aquellos que pueden participar en los diálogos, sino todos aquellos a quienes la decisión les puede repercutir: los pobres, los inmigrantes, los que presentan capacidades diferenciadas, entre otros. Debe considerarse los intereses de todos, incluso de quienes por cualquier razón no pueden participar — por ejemplo, las generaciones futuras-; y, sobre todo, debe posibilitarse que los potencialmente afectados los expongan y defiendan personalmente, que participen en la toma de decisiones, en la medida en que eso sea posible.

Esta situación ideal de diálogo se ve presidida por un principio ético procedimental: el principio de universalidad. En este tipo de éticas es conocido como el «principio discursivo» o el «principio discursivo de universalización», y es reformulado así: «Válidas son aquellas normas (y sólo aquellas normas) a las que todos los que puedan verse afectados por ellas pudiesen prestar su asentimiento como participantes en discursos racionales». ${ }^{36}$

Según este principio, un enunciado normativo - por ejemplo, un precepto, un derecho o una propuesta de acción - será moralmente correcto si todos los potencialmente afectados por él están dispuestos a brindarle su consentimiento - y en efecto lo hacen - tras un diálogo, celebrado en «condiciones de racionalidad» —en especial, de simetría y de ausencia de mecanismos de coacción-, porque los convencen las razones que se aportan en el seno mismo del diálogo, razones que siempre deben satisfacer intereses universalizables. Esto implica que el

35 Habermas, Jürgen. La necesidad de revisión de la izquierda. Madrid: Tecnos, 1991, p. 189.

36 Habermas, Jürgen. Facticidad y validez, sobre el Derecho y el Estado democrático de Derecho en términos de la teoría del discurso. Cuarta edición revisada. Introducción y traducción de Manuel Jiménez Redondo. Madrid: Trotta, 1998, p. 172. La cursiva es mía. Véase también del mismo autor «Ética del discurso. Notas sobre un programa de fundamentación». Op. cit., p. 86.

LA EDIFICACIÓN DE LA MORAL RELEVANTE PARA LA POLÍTICA Y EL DERECHO 
enunciado normativo no solo sea comprensible para todos los sujetos concernidos, sino también que resulte aceptable para todo aquel que resulte potencialmente afectado por sus consecuencias. Implica también que, para que una norma sea moralmente correcta —o para que esté moralmente justificada - en una situación ideal de diálogo, no basta con que sea universalizable: es necesario que cuente con la aprobación efectiva de todos los potencialmente afectados, en tanto participantes del diálogo, e incluso que sea susceptible de ser aprobada por quienes, por alguna razón, no pudieron participar. Como lo afirma Jürgen Habermas: «De conformidad con la [É]tica discursiva, una norma únicamente puede aspirar a tener validez cuando todas las personas a las que afecta consiguen ponerse de acuerdo en cuanto participantes de un discurso práctico (o pueden ponerse de acuerdo) en que dicha norma es válida». ${ }^{37}$

A pesar de sus semejanzas con la formulación kantiana, resulta evidente que el énfasis se desplaza aquí «desde aquello que cada uno puede querer sin contradicción alguna como ley general, a lo que todos de común acuerdo quieren reconocer como norma universal». ${ }^{38}$ En palabras de Karl-Otto Apel, la respuesta a la pregunta kantiana por las condiciones trascendentales de posibilidad y validez de la experiencia, hoy en día, ya «no nos remite a la filosofía kantiana de una "conciencia en general" trascendental», sino que «debe estar mediada por la auténtica adquisición de la filosofía en este siglo; por el reconocimiento del valor trascendental del lenguaje y, por tanto, de la comunidad lingüística». ${ }^{39}$ Se reinterpreta así el principio kantiano de universalidad, que servía como criterio para probar la corrección moral de las normas de acción, a un procedimiento en virtud del cual las discusiones práctico-morales entre los sujetos pueden encontrar un fundamento racional a través de la racionalidad comunicativa. Por lo tanto, como sostiene Axel Honneth, en lugar de utilizar el principio de universalidad — como lo entendía el pensamiento kantiano- como un test de validez moral que un sujeto solitario efectúa consigo mismo, las éticas comunicativas trasladan ese examen a un acto comunicativo «que no finge representar simplemente un contrato único, en el sentido de las teorías contractuales, sino que es exigido como una discusión que ha de efectuarse realmente.» De acuerdo con esto, solo el diálogo efectuado en condiciones de racionalidad, entre todos los potencialmente afectados, puede determinar si una norma de acción es moralmente correcta; y, al revés: «una norma de acción tiene validez en última instancia solo cuando todos los afectados por ella, en tanto participantes de un diálogo fáctico, alcanzan un consenso sobre si la norma debe entrar en vigencia o permanecer vigente». ${ }^{40}$ Se considera, en ese sentido, que la ética discursiva ha emprendido «una supuesta

37 Habermas, Jürgen. «Ética del discurso. Notas sobre un programa de fundamentación». Op. cit., p. 86. 
"superación" del universalismo monológico-formal de Kant en un universalismo dialógico-formal»; es decir, ha transitado desde el «yo» de la visión kantiana hacia el «nosotros» de una comunidad de diálogo. ${ }^{41}$

Este principio discursivo de universalización hace igualmente imprescindibles la participación, la deliberación y el consenso, pues, si bien el consenso es el objetivo, la participación y la discusión son el camino que necesariamente hay que seguir para alcanzarlo. Dicho en otras palabras, no hay enunciado normativo válido si no es por la vía de la participación, la deliberación y el consenso. Esto se debe a que el simple acuerdo no asegura que la decisión sea racional, ni que su justificación moral sea correcta. Para conseguirlos, se tiene que transitar por un procedimiento racional, en el que la participación y la deliberación ocupan un lugar destacado: solo a través de ellas podrán examinarse adecuadamente los intereses comunes y las distintas posiciones en pugna - lo que reduce la posibilidad de una interpretación equivocada-, a fin de adoptar una decisión consensuada que, al cumplir con el principio discursivo de universalización, merezca la aquiescencia universal. Se rechaza así la posibilidad de consentimientos previos o implícitos por considerárseles expresiones de una mentalidad monológica. ${ }^{42}$

Resulta importante insistir en que la participación y la deliberación deben realizarse en un escenario de diálogo donde rijan las «condiciones de racionalidad», a fin de que todos los potencialmente afectados puedan participar en condiciones de simetría y donde finalmente triunfe la fuerza del mejor argumento y no alguna circunstancia interna o externa al diálogo que afecte la libertad de elección de las personas. Esto último significa que una norma solo obliga moralmente si el sujeto tiene conciencia de que la considera moralmente correcta, es decir, de que no ha sido impuesta. Las «condiciones de racionalidad» del discurso se han agrupado en tres categorías: (i) las referidas a la esfera lógica de los argumentos - que buscan que los argumentos sean atinados y convincentes, desde el punto de vista de sus propiedades intrínsecas, para verificar o rechazar las aspiraciones de validez_; ${ }^{43}$ (ii) la relacionada con la esfera dialéctica de los procedimientos — que agrupa a los presupuestos pragmáticos para la búsqueda cooperativa de la verdad o corrección,

41 Wellmer, Albrecht. Éticaydiálogo. Barcelona: Anthropos, 1994,p.38. Javier Muguerza defiende unaopinión similar: «[que] el sujeto de la acción moral, al igual que el sujeto del conocimiento científico, no es nunca uno-comoloerael sujeto hipotético kantiano-sino muchos, a saber, una comunidad (e incluso múltiples comunidades)desujetos reales. Poresoes porloquesetiendehoyadecirqueelejerciciodelaracionalidad no puede consistir en un monólogo, sino que precisa de un diálogo entre tales sujetos reales". En Desde la perplejidad. Ensayos sobre la ética, la razón y el diálogo. Madrid y México D.F.: Fondo de Cultura Económica, 1990, p. 161.

42 Confróntese Habermas, Jürgen. «¿Afectan las objeciones de Hegel contra Kant también a la ética del discurso?». En Aclaraciones a la ética del discurso. Op. cit., pp. 22-23.

43 Se han mencionado comoejemplos las siguientes reglas: (i) ningún hablante debe contradecirse; (ii) todo hablante que aplique el predicado $F$ a un objeto $A$ debeestar dispuestoa aplicar el predicado $F$ atodo objeto que se parezca a A en todos los aspectos importantes; $y$ (iii) diversos hablantes no pueden usar la misma expresiónconsignificadosdiferentes. VéaseHABERMAS,Jürgen. «Éticadeldiscurso. Notassobreunprograma de fundamentación». Op. cit., p. 110; y Alexy, Robert. Teoría de la argumentación jurídica, La teoría del discurso racional como teoría de la fundamentación jurídica. Traducción de Manuel Atienza e Isabel Espejo. Madrid: Centro de Estudios Constitucionales, 1989, p. 185.

LA EDIFICACIÓN DE LA MORAL RELEVANTE PARA LA POLÍTICA Y EL DERECHO 
como las referidas a la responsabilidad y honestidad de los participantes, así como a las cargas de la argumentación-,${ }^{44}$ y (iii) las que conciernen a la esfera retórica de los procesos — que buscan que el discurso argumentativo sea un proceso de comunicación suficientemente próximo a las condiciones ideales de simetría y ausencia de coacción-.$^{45}$

La deliberación implica el intercambio de opiniones con el objetivo de convencer a los demás, a través de argumentos sobre lo verdadero o correcto de una posición, así como dejarse convencer sobre ellos cuando se oponen argumentos mejores. A través de este proceso comunicativo abierto, los participantes realizan una reflexión trascendental para analizar las diversas posiciones que hayan sido presentadas; se examinan una y otra vez los diversos argumentos que en tal escenario se formulen, y se ajustan sucesivamente sus posiciones discrepantes, e incluso contrapuestas, con el objetivo común de encontrar la satisfacción de necesidades compartidas - incluso de quienes no participan o no pueden participar en el diálogo-

La determinación de los principios y normas morales requerirá de la capacidad de suscitar consenso mediante argumentos entre personas racionales. Al encontrase referidos a cuestiones prácticas de la vida, dichos argumentos no consistirán tan solo en una cadena deductiva de enunciados con consistencia lógica. Tampoco en una demostración razonable sobre las consecuencias que se pueden derivar de determinadas premisas. Consistirán principalmente en «buenas razones» susceptibles de provocar el asentimiento de todos los posibles afectados. ${ }^{46}$

El consenso se alcanza aquí cuando todos los potencialmente afectados, o por lo menos todos los que hayan querido y podido participar, prestan su asentimiento a alguna posición, luego de haber quedado plenamente convencidos de que esta se encuentra completamente justificada, por estar sustentada en las mejores razones expuestas que cumplen con satisfacer intereses universalizables. Se aparta así de la negociación, pues esta última no tiene como objetivo encontrar racionalmente lo verdadero o lo correcto, sino la posibilidad de obtener un provecho al hacer valer los propios intereses, las propuestas ventajosas, la amenaza de perjuicios,

44 Se han indicado como ejemplos las siguientes reglas: (i) todo hablante solo puede afirmar aquello en lo que verdaderamente cree; (ii) todo hablante debe, cuando se le pide, fundamentar lo que afirma, a menos que puedadar razonesquejustifiquenel rechazar unafundamentación; $y$,(iii)todohablanteque introduzca un enunciado o norma que no es objeto de la discusión debe dar una razón que lo justifique. Confróntese Habermas, Jürgen. «Ética del discurso. Notas sobre un programa de fundamentación». Op. cit., p. 111; y Alexy, Robert. Teoría de la argumentación jurídica... Op. cit., pp. 185 y 188.

45 Se han señalado como ejemplos de esta esfera las siguientes reglas: (i) todo sujeto capaz de hablar o de actuarpuedetomarparteeneldiscurso;(ii)todosdebentenerlibertaddediscusión,estoes:(a)todospueden cuestionarcualquierafirmación;(b)todospuedenintroducircualquierafirmaciónaldiscurso;(c)todospueden expresarsusopiniones,deseosynecesidades;porúltimo,(iii)aningúnhablantepuedeimpedírseleelusode losderechosprecedentementemencionados, mediantecoacciónexternaointernaaldiscurso.Confróntese HABERMAS, Jürgen. «Ética del discurso. Notas sobre un programa de fundamentación». Op. cit., pp. 112-113; y Alexy, Robert. Teoría de la argumentación jurídica...Op. cit., p. 189.

46 Esto se debe, a que «[I]a validez de una norma consiste en su potencialidad para ser reconocida, lo cual tiene que demostrase discursivamente; una norma válida merece reconocimiento porque, y en la medida en que, sea aceptada —es decir, reconocida como válida - también bajo condiciones de justificación (aproximativamente) ideales". Habermas, Jürgen. Verdad y justificación. Op. cit., p. $\mathbf{5 3}$. 
aun cuando eso suponga la desatención de los intereses de otros posibles afectados. $^{47}$

El consenso aquí no equivale, pues, al uso que se hace de esa expresión en el ámbito político o jurídico, ya que no es el resultado de una negociación en la que todos ceden una parte y concuerdan en otra, de modo que nadie queda plenamente satisfecho. Tampoco equivale al simple acuerdo que se adopta como grupo, sea por unanimidad o mayoría. Es un consenso que se logra mediante el consentimiento de todos y cada uno de los individuos potencialmente afectados — o por lo menos de los que hayan podido y querido participar-, luego de haber quedado plenamente convencidos de que las razones que se asumen son las mejores. Un consenso que se construye necesariamente sobre la base de convicciones y que cuando cuenta con una raíz kantiana requiere que las razones que las sustentan no sean impuestas y que satisfagan intereses universalizables. Por esa razón, en este tipo de posturas, el simple acuerdo fáctico no dota de validez moral a una norma, conducta o decisión, sino lo hace el asentimiento que prestan los individuos luego de quedar convencidos de que ella cuenta con una justificación moral al satisfacer los principios de autonomía y universalidad que —en los modelos de raigambre humanista - se orientan siempre hacia el desarrollo integral de la persona. ${ }^{48}$

Esta idea del consenso no solo supone la posibilidad de que las personas puedan brindar su consentimiento, sino también la de negarla cuando no han sido convencidas. Esto se debe a que «[d]el ejercicio de la racionalidad no se sigue lógicamente el consenso: cabe tanto la convergencia como la divergencia, la coincidencia entre los participantes como el enfrentamiento de sus opiniones». ${ }^{49}$ Dos consecuencias se desprenden al respecto. En primer lugar, la imposibilidad lógica, para una racionalidad intersubjetiva, de hablar de una única respuesta correcta para una

47 «Si como afirma Habermas, el discurso práctico consiste en un "aclararse sobre un interés común” [...], estaactividadnuncatendrámás sentidonipodrárecabar más urgenciaquecuandosepresentan intereses divergentesyaúncontradictorios. Elinteréscomúnestriba,entonces,enunarreglo“justo"o "equitativo"de un conflicto de intereses; este arreglono puede hallarseen una simpletransacción, truequeonegociación de intereses contrapuestos, sino en la formación de un juicio común sobre la índole de tales intereses contrapuestos, un ajuste de los intereses que ha de pasar necesariamente por la ponderación de los diferentes intereses particulares". Velasco, Juan Carlos. La teoría discursiva del derecho: sistema jurídico y democraciaen Habermas. Madrid:CentrodeEstudios PolíticosyConstitucionales,Boletín OficialdelEstado, 2000, p. 57.

48 Sinperjuiciodeello,cabeseñalarque, desdesectorescercanosalaséticasdeontológicasderaízkantiana,se criticaqueelconsensoseaunelementorelevanteparadeterminarloqueesmoralmenteválido-oinválido. Para ellas, la validez moral se determina en función de los principios de autonomía y universalidad y no delconsensofácticoquepuedaalcanzarse-pormáscorrespondenciaquetengaconambosprincipios-. Para estos sectores, si se satisfacen los principios de autonomía y universalidad, la norma, conducta o decisión será moralmente válida, independientemente de que se haya alcanzado o no un acuerdo. Ernesto Garzón Valdés lo expresa así: «El consenso fáctico no es una buena pauta para juzgar la calidad moral de disposiciones normativas. Lo es, desde luego, para la estabilidad del sistema que ellas integran, pero una cosa es su estabilidad y otra su legitimidad». «Lo íntimo, lo privado y lo público». Claves de Razón Práctica, no 137, noviembre de 2003, p. 20. Naturalmente, las éticas basadas en el consenso que se examinan aquí, al tener una raíz kantiana, exigen que el consenso se base sobre razones que satisfagan los principios de autonomía y universalidad, siempre orientados al desarrollo integral de la persona.

49 Velasco, Juan Carlos. La teoría discursiva del derecho... Op. cit., p. 73.

\section{LA EDIFICACIÓN DE LA MORAL RELEVANTE PARA LA POLÍTICA Y EL DERECHO}


cuestión práctica, como lo hacía Ronald Dworkin: ${ }^{50}$ «La suposición de la existencia, independientemente del procedimiento, de una única respuesta correcta para cada cuestión práctica es una tesis ontológica que tiene poco a su favor y contra la que se puede aducir mucho». ${ }^{51}$ Otra cosa es que el participante defienda su postura como si se tratara de la única respuesta correcta —es decir, al hacer de dicha tesis una idea regulativa-, aunque esté dispuesto a aceptar otras respuestas posibles, siempre que se le demuestre su existencia con otras razones mejores. En segundo lugar, se abren las puertas a la alternativa del disenso: para las éticas comunicativas, este no constituye un elemento perturbador; por el contrario, se presenta como un elemento fecundo y renovador para perfeccionar el orden moral vigente, para alcanzar nuevos consensos y para garantizar la convivencia pacífica. Lo dice el propio Habermas: «cuanto más abstracto el acuerdo, tanto más plurales los disensos con que podemos vivir sin violencia». ${ }^{52}$

En cualquiera de los casos, las decisiones o acuerdos que se adopten son siempre revisables y susceptibles de ser sustituidos. No solo porque no se descarta el error o la posibilidad de que alguno de los participantes actúe indebidamente motivado por intereses egoístas, sino también porque es posible que aparezcan nuevas y mejores razones que justifiquen el cambio de decisión — verbigracia, porque los adelantos científicos y tecnológicos aportan nuevas luces sobre el problema que fue objeto de solución-. De esta manera, las normas morales no son consideradas definitivas o absolutas, sino que se abren a la posibilidad de ser sustituidas por otras mejores.

Como consecuencia de revisiones ulteriores, la ética discursiva ha desarrollado matices y precisiones. Por lo menos la teoría ética habermasiana ha advertido la distinta problemática que representa el «discurso de fundamentación» del «discurso de aplicación». El «discurso de fundamentación» se refiere a la validez abstracta de los enunciados o juicios de valor, sin referencia alguna a una situación concreta. Lo relevante para este primer tipo de discurso es la validez de la misma norma, con

50 Véase su trabajo Los derechos en serio. Segunda edición de la primera edición en español de 1984. Traducción de Marta Guastavino. Barcelona: Ariel, 1989 [1977].

51 Alexy, Robert. Teoría de la argumentación jurídica... Op. cit., p. 302. Que exista una conexión entre una determinada filosofía moral y política con la concepción que se tenga sobre el Derecho, y la manera de trabajarconlojurídico,esunaafirmaciónquehoyen díapuedeseraceptada.Sinembargo, afirmarqueexiste una única respuesta correcta — desde un punto de vista moral, político y jurídico—a la que se puede llegar demaneraobjetivaesunatesisimposiblededemostrar, porquehabríaqueponerseentodaslassituaciones posibles para la problemática que se pretende solucionar; incluso en aquellas que no se pudieron prever en el momento de fundamentar la respuesta. Se necesitaría de un «juez Hércules», como el propio Ronald Dworkin lo reconoce. Por otro lado, una tesis semejante podría llevar a un objetivismo moral que - sin ser negativoensímismo-podríadarlugaraciertaspatologíasenperjuiciodelalibertaddelindividuo,comopor ejemploimponerunamoralpersonalcomocriteriodejusticiapararegularlasrelacionessocialesoimponer unamoralpúblicapararegularlavidaprivadadelaspersonas-conconsecuenciasdiversas,enfunciónala perspectivamoral, políticaojurídicaqueseadopte-.Sepodríaargüirqueestaspatologíassalendelmarco teóricodelapropuestadelaúnicarespuestacorrectayqueenunasociedaddemocrática-pordefinicióntales patologías no son posibles. Sin embargo, la historia nos enseña que la realidad es diferente, que en el funcionamientodelpoderseproducendesviacionesqueseconviertenenauténticaspatologíasquedañanla libertad del ser humano, por lo que el riesgo que se acusa no debe ser dejado de lado.

52 Elpensamiento postmetafísico. Versión castellana de Manuel Jiménez Redondo. Madrid: Taurus, 1990, p. 181. 
independencia de su aplicación a una situación particular. El «discurso de aplicación», en cambio, se refiere a los enunciados o juicios de valor que deben aplicarse a una situación concreta. Lo relevante para este segundo tipo de discurso no es la validez de la norma, sino su adecuación ante circunstancias determinadas a fin de decidir su aplicación. «La [É] tica del discurso — dice Habermas — ha aprendido la lección, y distingue entre la validez —o la justicia— de las normas y la corrección de los juicios singulares que con base a una norma válida distinguen una determinada acción como mandada». Agrega además que para determinar «[c]ómo actuar correctamente en las circunstancias dadas" no se puede decidir, considerando las cosas analíticamente, con un único acto de fundamentación —o dentro de los límites de un único tipo de argumentación - sino que exige la secuencia de dos pasos argumentativos, a saber, la fundamentación y la aplicación de las normas». ${ }^{53}$ En el primer paso, se busca determinar, en abstracto, las normas válidas que resultan pertinentes para regular paradigmáticamente una materia necesitada de regulación. Al ser una reflexión abstracta, no se puede exigir a los participantes la carga de considerar situaciones futuras que en ese momento no resulten previsibles. Estos solo tienen la carga de fundamentar y de decidir teniendo en consideración las situaciones típicas que puedan preverse en ese momento. Estamos aquí en el ámbito del «discurso de fundamentación» y el principal criterio que lo rige es el principio discursivo de universalización. En el segundo paso se pretende determinar, entre todas las normas que han sido fijadas como válidas, la que resulte más adecuada para solucionar el caso concreto a decidir, es decir, para determinar la acción que se debe seguir ante unas circunstancias dadas. Esto se debe a que, en el momento de examinar un caso particular, es posible que se presenten circunstancias o consecuencias que no fueron previstas en el momento de la fundamentación, constelaciones particulares de situaciones no previsibles que hacen necesario acudir a un criterio complementario. Estamos esta vez ante el «discurso de aplicación» y el criterio que lo orienta es el «principio de adecuación». Este equivale a un juicio de ponderación que se realiza sobre normas válidas prima facie, que de manera pertinente y relevante concurren a la solución de un caso concreto, para determinar entre ellas la que resulte más apropiada para solucionar la problemática planteada. Con esto, «[e]l papel que desempeña el principio de universalización en los discursos de fundamentación es asumido en los discursos de aplicación por el principio de adecuación. Únicamente los dos principios juntos agotan la idea de imparcialidad». ${ }^{4}$ Se intenta transitar así de la teoría a la acción y proporcionar una respuesta racional, integral y operativa al tratamiento de las cuestiones prácticas.

53 «Aclaraciones a la ética del discurso». Op. cit., pp. 145 y 145-146 respectivamente.

$54 \mathrm{lbid}$., p. 147. «El problema [...] comparece con claridad en el caso de las colisiones de normas. En efecto, en esos casos hay que examinar cuál de las normas válidas prima facie que presentan su candidatura a la aplicaciónserevelacomolaadecuadaaunasituación descritaconlamayorexhaustividadposibleentodas sus características relevantes. Las normas que ceden la primacía a la aplicadaen cada caso no pierden por ello su validez, sino que forman junto con todas las demás reglas válidas un orden coherente». Ibid., p. 148.

LA EDIFICACIÓN DE LA MORAL RELEVANTE PARA LA POLÍTICA Y EL DERECHO 
En definitiva, las éticas comunicativas nos ofrecen otro método objetivo para determinar la validez moral de nuestros enunciados y juicios de valor, para generar y examinar normas morales válidas, así como para resolver los problemas morales concretos o conflictos de acción que se puedan presentar. Si bien dicho método es diseñado mediante condiciones ideales, que en conjunto configuran una situación de diálogo igualmente ideal, no cabe duda de que «tal idealidad sirve para orientar nuestros diálogos cotidianos sobre la validez de normas, para medir la insuficiencia de los mismos y para dar sentido al hecho cotidiano de entrar en un diálogo». ${ }^{55}$ Es decir, sirve como una idea regulativa que nos proporciona, además, una dirección para la acción y un criterio para la crítica de nuestras acciones concretas; un canon para la práctica y una medida para examinar las desviaciones que se puedan producir respecto del modelo comunicativo propuesto, así como para determinar la calidad del consenso realmente alcanzado. ${ }^{56}$

\section{BREVE REFLEXIÓN FINAL}

Si queremos construir una sociedad libre, abierta, plural y democrática, donde la persona pueda encontrar mecanismos adecuados para el pleno desarrollo de su dignidad, es decir, para alcanzar con su esfuerzo pero con la ayuda de todos su autonomía moral, se requiere que la política y el Derecho se encuentren comprometidos efectivamente con su realización. Al tener esos objetivos una manifiesta dimensión moral, el poder político y el Derecho que quieran tomarlos en serio deberán estar relacionados con una moralidad orientada a alcanzar esos objetivos. Si los fenómenos políticos o jurídicos prescindiesen de esa vinculación, no podría garantizarse el desarrollo integral de la persona y se correría el peligro de caer en un pragmatismo deshumanizante, si no en una situación de corruptela generalizada, o incluso en un estado de dominio y sumisión regido por el uso exclusivo de la fuerza.

Para determinar cuál es la moralidad relevante que debe relacionarse con la política y el Derecho es necesario asumir una postura ética. El uso de una u otra perspectiva puede llevarnos a la edificación de moralidades con contenido distinto. Las líneas precedentes han sido ejemplos de ello.

Como quiera que la política y el Derecho se relacionen con alguna moralidad — generalmente con la moral vigente en una sociedad —, la reflexión moral debe ser satisfactoriamente abordada, más si se aspira a

55 Apel, Karl-Otto, Adela Cortina y otros. «Prólogo». Op. cit., p. 7.

56 «La anticipación de una situación ideal de habla es lo que garantiza que podamos asociar a un consenso alcanzado fácticamente la pretensión de ser un consenso racional. Al propio tiempo, esa anticipación es unainstanciacríticaquenospermiteponerencuestióntodoconsensofácticamentealcanzadoy procedera comprobarsipuedeconsiderarseindicadorsuficientedeunentendimientoreal». HABERMAS, Jürgen. Teoríade la acción comunicativa: complementos y estudios previos. Op. cit., p. 105. 
contribuir a la construcción de una sociedad orientada hacia el desarrollo integral de la persona.

En el caso de la enseñanza y del trabajo jurídico, esa labor debe ser incentivada. La orientación que adopte el Derecho y los fenómenos jurídicos depende de ello. Así, por ejemplo, no será lo mismo estudiar y operar lo jurídico desde un iusnaturalismo abstracto, intemporal, que postule la primacía de la moral sobre el ordenamiento positivo, que desde un positivismo excesivamente formalista que prescinda de cualquier conexión con la moral. A igual conclusión podría llegarse en relación con el poder y los fenómenos políticos.

En lo que a mí respecta, coincido con quienes sostienen que el Derecho necesita a la moral, que la moral interactúa con el poder y que tiene un importante espacio en el Derecho, y que el poder se relaciona con ambos para hacer que lo justo sea fuerte y que lo fuerte sea además justo, a condición de respetar cada uno las reglas de juego de los otros. ${ }^{57} \mathrm{Tal}$ conexión entre la moral, la política y el Derecho no significa identificación, ni mucho menos reducción de alguna en las otras. Aunque estén interrelacionadas, cada una cumple con especiales funciones a pesar de que sus fines puedan ser los mismos. Eso significa que la política y el Derecho no pueden prescindir de la moral para ser moralmente correctas, ni la moral puede prescindir de la política y el Derecho si es que quiere ser fuerte y tener exigibilidad jurídica. Tal distinción, aunque asume la conexión, pone de manifiesto que no todo lo políticamente conveniente, o jurídicamente válido, es moralmente aceptable; y que no todo lo que en política conviene, o es moralmente justo, logra ser asumido por el poder e incorporado a lo jurídico. Ello se debe a que la moral, la política y el Derecho no se rigen por un mismo código de reglas.

LA EDIFICACIÓN

DE LA MORAL

RELEVANTE PARA

LA POLÍTICA Y EL DERECHO 